\title{
Novel degradative pathway of 4-nitrobenzoate in Comamonas acidovorans NBA-10
}

\author{
Peter E. J. Groenewegen, ${ }^{*}$ Pieter Breeuwer, Joop M. L. M. van Helvoort, \\ Alette A. M. Langenhoff, Floris P. De VRies and Jan A. M. De Bont \\ Division of Industrial Microbiology, Department of Food Science, Agricultural University, PO Box 8129, \\ 6700 EV Wageningen, The Netherlands
}

(Received 29 October 1991; revised 23 March 1992; accepted 28 April 1992)

\begin{abstract}
A Comamonas acidovorans strain, designated NBA-10, was isolated on 4-nitrobenzoate as sole carbon and energy source. When grown on 4-nitrobenzoate, it was simultaneously adapted to 4-nitrosobenzoate and 4hydroxylaminobenzoate but not to 4-hydroxybenzoate or 4-aminobenzoate. In cell extracts with NADPH present, 4-nitrobenzoate was degraded to 4-hydroxylaminobenzoate and 3,4-dihydroxybenzoate. Partial purification of the 4-nitrobenzoate reductase revealed that 4-nitrobenzoate is degraded via 4-nitrosobenzoate to 4-hydroxylaminobenzoate. The substrate specificity of the enzyme was narrow and NADPH was 15 times more effective as a cofactor than NADH. The results provide evidence for a novel pathway for aerobic degradation of 4nitrobenzoate, since neither 4-hydroxybenzoate nor 4-aminobenzoate were involved in the degradative pathway.
\end{abstract}

\section{Introduction}

Aromatic nitro-compounds, e.g. nitrophenols, nitrotoluenes and nitrobenzoates, are used in the manufacture of pesticides, dyes, explosives and industrial solvents. These compounds enter industrial waste streams and in several instances accumulate in the environment. The biological conversion of these compounds is consequently of great interest. Furthermore, microbes degrading nitro-aromatics may contain enzymes yielding hydroxylated aromatics. Such enzymes are of interest because hydroxylated aromatics are chemically difficult to prepare. Microbial methods for the preparation of hydroxylated aromatics have been considered previously in the biotransformation of halogenated aromatic compounds (Groenewegen et al., 1992).

In general two different systems have been described for the removal of the nitro-group from nitro-aromatic compounds by micro-organisms. In the first pathway, the nitro substituent is directly removed as nitrite, as demonstrated for the metabolism of $o$ - and $p$-nitrophenol (Zeyer \& Kearney, 1986; Spain et al., 1979), and in the metabolism of 2,6-dinitrophenol (Bruhn et al., 1987).

\footnotetext{
* Author for correspondence. Tel. 8370 84749; fax 837084978 .

Abbreviations: 4-ABA, 4-aminobenzoate; 4-HBA, 4-hydroxybenzoate; 4-NBA, 4-nitrobenzoate; 3,4-diHBA, 3,4-dihydroxybenzoate; 4HABA, 4-hydroxylaminobenzoate; 4-NOBA, 4-nitrosobenzoate.
}

In the second pathway, the nitro-group is reduced by a nitroreductase to an amine via nitroso and hydroxylamino intermediates (Schackmann \& Müller, 1991; Kinouchi \& Onishi, 1983; Liu et al., 1984; McCormick et al., 1976). Such reduction of the nitro-aromatic compound to the corresponding amino-aromatic compound has been demonstrated in various organisms which are able to use the nitro-aromatic compound as an electron acceptor. The amino intermediate is a metabolic endproduct in these organisms (Rafii et al., 1991; Schackmann \& Müller, 1991).

In addition, the involvement of nitroreductases in the complete degradative pathways of nitro-aromatic compounds has also been reported (Durham, 1956; Germanier \& Wuhrmann, 1963; Haller \& Finn, 1978). In the aerobic metabolism of 2- and 4-nitrobenzoate, reduction of the nitro-group via nitroso- and hydroxylaminobenzoate was demonstrated (Cain, 1966a, $b$; Cartwright \& Cain $1959 a, b)$. The amino intermediate transiently accumulated during growth on the nitro-aromatic compound but no evidence was provided that the aminoaromatic compound was an intermediate in the degradative pathway of 2-nitrobenzoate and 4-nitrobenzoate (4NBA) (Cain 1966a; Ke et al., 1958; Cain \& Cartwright, 1960). In Nocardia erythropolis, degradation of 4-NBA after reduction was suggested to proceed via 3,4dihydroxybenzoate (3,4-diHBA) with some 4-nitrocatechol formed, probably from a side reaction. Based on 
oxygen consumption rates of whole cells, an intermediary role for 4-hydroxybenzoate (4-HBA) in Nocardia erythropolis was also suggested (Cartwright \& Cain, $1959 a, b)$.

In this paper, evidence is presented for a new metabolic pathway in the degradation of 4-NBA involving neither 4-HBA nor 4-aminobenzoate (4-ABA) as intermediates.

\section{Methods}

Media and culture conditions. Enrichments of 4-NBA-utilizing bacteria from various soil and water samples were done at $30^{\circ} \mathrm{C}$ in $100 \mathrm{ml}$ serum flasks containing $10 \mathrm{ml}$ mineral salts medium with $1 \mathrm{mM}$ 4-NBA. After incubation for I week, plates of yeast/glucose agar were streaked with material from the enrichment cultures. Colonies were streaked to purity on the same medium and the ability to grow on 4NBA was examined by growing the pure cultures in liquid medium in the presence and absence of $1 \mathrm{mM}-4-\mathrm{NBA}$. The pure culture exhibiting the highest growth rate on 4-NBA was designated NBA-10. It was classified by the National Collections of Industrial and Marine Bacteria (NCIMB, Aberdeen, UK) as a strain of Comamonas acidovorans. Strain NBA-10 was routinely grown in a chemostat $(D=$ $0 \cdot 1 \mathrm{~h}^{-1}$ ) under carbon-limited conditions at $\mathrm{pH} 7.0$ and at $30^{\circ} \mathrm{C}$. The mineral salts medium in the medium reservoir contained $20 \mathrm{~mm}-4-$ NBA. Strain NBA-10 was also grown on 4-HBA, 3,4-diHBA or succinate in the chemostat.

Experiments with resting cells. Cells grown in a chemostat were harvested by centrifugation at $16000 \mathrm{~g}\left(10 \mathrm{~min}\right.$ at $\left.4{ }^{\circ} \mathrm{C}\right)$, washed in potassium phosphate buffer ( $\mathrm{pH} 7 \cdot 0,50 \mathrm{mM})$ and resuspended in the same buffer. Endogenous oxygen uptake by suspensions $(3 \mathrm{ml})$ of washed cells was measured for at least $3 \mathrm{~min}$ at $30^{\circ} \mathrm{C}$ using a YSI model 53 monitor equipped with a YSI model 5331 polarographic oxygen probe (Yellow Springs Instruments, USA). Subsequently, $0.1 \mathrm{ml}$ of a substrate solution ( $30 \mathrm{~mm}$ ) was added and the oxygen uptake was recorded for at least another $5 \mathrm{~min}$.

Experiments to determine the aerobic degradation rate of 4-NBA and 4-nitrosobenzoate (4-NOBA) by washed cell suspension $(10 \mathrm{ml})$ were done in $100 \mathrm{ml}$ serum flasks in a shaking water-bath $\left(30^{\circ} \mathrm{C}, 1 \mathrm{~Hz}\right)$. Degradation of 4-NBA and 4-NOBA was also examined by incubating $100 \mathrm{ml}$ serum flasks under stationary (oxygen-limited) conditions at $30^{\circ} \mathrm{C}$. Before starting anaerobic experiments, incubation flasks were flushed for at least $15 \mathrm{~min}$ with $\mathrm{N}_{2}$ gas (oxygen-free). The degradation of 4-NBA or 4-NOBA by whole cells was started by adding substrate with a gas-tight syringe from a $\mathrm{N}_{2}$-flushed concentrated stock solution. Samples were periodically withdrawn from the incubation mixture (with a gas-tight syringe) and immediately centrifuged $(10000 \mathrm{~g})$; the supernatant was then analysed by HPLC.

Experiments with cell-free extracts. Cell-extracts were prepared by disrupting washed cell suspensions by ultrasonic disintegration (Branson Sonic Power) for $8 \times 15 \mathrm{~s}$ with a power input of $10 \mathrm{~W}$ at $0{ }^{\circ} \mathrm{C}$. The resulting homogenate was centrifuged at $30000 \mathrm{~g}$ for $20 \mathrm{~min}$ at $4{ }^{\circ} \mathrm{C}$. The supernatant was used as crude cell-free extract and contained $10-15 \mathrm{mg}$ protein $\mathrm{ml}^{-1}$.

Experiments to determine the degradation of 4-NBA and 4hydroxylaminobenzoate (4-HABA) by cell-free extracts were done in $5 \mathrm{ml}$ tubes with gas-tight rubber septa. Anaerobic experiments in these tubes were done as described above for the serum flasks. The reaction was stopped by addition of $6 \mathrm{M}-\mathrm{HCl}$ to give a final concentration of $0.6 \mathrm{M}$. The precipitated protein was removed by centrifugation and samples of the supernatant were analysed by HPLC.
4-NBA reductase assay. 4-NBA consumption by cell-free extracts or partially purified enzyme was measured spectrophotometrically by following at $340 \mathrm{~nm}$ the rate of oxidation of NADPH in the presence of 4-NBA. In some experiments, 4-NBA reductase activity was determined by using HPLC to monitor the degradation of 4-NBA.

Partial purification of 4-NBA-reductase. Protein was precipitated with saturated ammonium sulphate solution, centrifuged at $10000 \mathrm{~g}(15 \mathrm{~min}$ at $4{ }^{\circ} \mathrm{C}$ ), dissolved in $10 \mathrm{ml} \mathrm{Tris/} / \mathrm{HCl}(50 \mathrm{mM}, \mathrm{pH} 8.0)$, dialysed against the same buffer and applied to a DEAE-Sepharose CL-6B column (Pharmacia). The enzyme was eluted with a linear gradient of $0-0.5 \mathrm{M}$ $\mathrm{NaCl}$ in Tris/ $\mathrm{HCl}(50 \mathrm{~mm}, \mathrm{pH} 8.0)$. Fractions of $10 \mathrm{ml}$ were collected and active fractions were pooled, concentrated with ammonium sulphate and dialysed as above. This concentrated fraction was applied onto a FPLC Mono Q column (Pharmacia), and the enzyme was eluted with a linear gradient of $\mathrm{NaCl}(0-0.5 \mathrm{M})$.

Chemicals. 4-HABA was synthesized chemically (Bauer \& Rosenthal, 1944) and was free of 4-ABA as determined by HPLC analysis. 4-NOBA was synthesized by the method described by Cartwright \& Cain (1959a) and was free of 4-NBA and 4-ABA.

All other chemicals were of the highest purity commercially available.

Analytical methods. The synthesized 4-HABA was also analysed with a Finnegan Q 70 mass spectrometer. The DCI (direct current introduction) probe was heated to $400^{\circ} \mathrm{C}$. The source temperature was $150^{\circ} \mathrm{C}$ and ionization took place at $70 \mathrm{eV}$. The [quadruple] mass filters were kept at $70{ }^{\circ} \mathrm{C}$. The measurements were with $100 \mathrm{ng} 4-\mathrm{HABA}$ and 3,4-diHBA dissolved in ethyl acetate dried with $\mathrm{Na}_{2} \mathrm{SO}_{4}$. Since DCIMS resulted in a disturbed picture, the standards and extracted HPLC samples were scanned by CID (collision induced decomposition) MS with DCI introduction.

The purity of the chemically synthesized 4-NOBA and 4-HABA were measured in DMSO- $d_{6}$ solution on a Bruker AC 200E instrument.

Concentrations of 4-NBA, 4-NOBA, 4-HABA and 3,4-diHBA were routinely determined by reversed phase HPLC on a C-18 column (200 $\times 3 \mathrm{~mm}$, Chrompack). For determinations of 4-NBA and 4-NOBA, acetonitrile/water/acetic acid $(40: 59: 1$, by vol.) and for 4-HABA and 3,4-diHBA, acetonitrile $/ 0.005 \mathrm{M}$-sulphuric acid $(10: 90, \mathrm{v} / \mathrm{v})$ were used as mobile phases. The concentration of NADP was determined by HPLC using a C- 18 column with 50 mm-phosphate buffer ( $\mathrm{pH} \mathrm{7.0)}$ ) as mobile phase.

Protein contents of whole cells and cell extracts were determined by the Lowry method using crystalline bovine serum albumin as a standard.

Ammonium was determined by following the oxidation of NADH in the presence of 2-oxoglutarate and L-glutamate dehydrogenase using a test kit from Sigma (kit number 170-A).

\section{Results}

\section{Isolation and characterization of the 4-NBA-degrading organisms}

Several 4-NBA-utilizing strains were isolated from aerobic enrichment cultures with 4-NBA as sole carbon and energy source. One organism, designated strain NAB-10, was a motile rod and transmission electron microscopic photographs showed it possessed one to six polar flagella. It was further characterized by the National Collections of Industrial and Marine Bacteria Limited as Gram-negative and oxidase-positive. The 


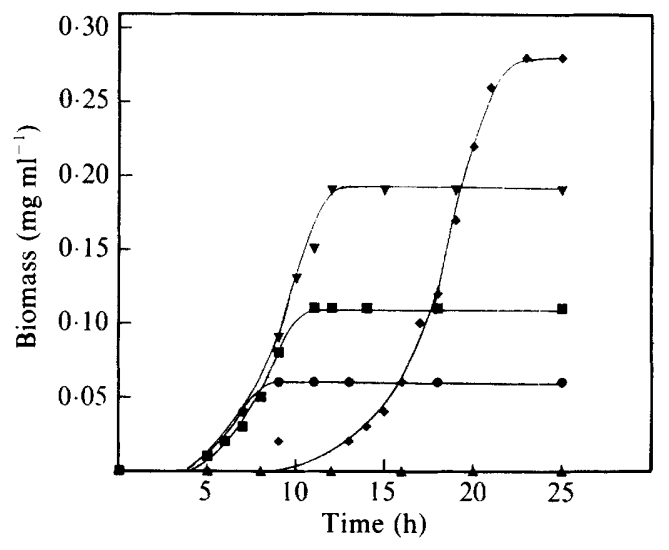

Fig. 1

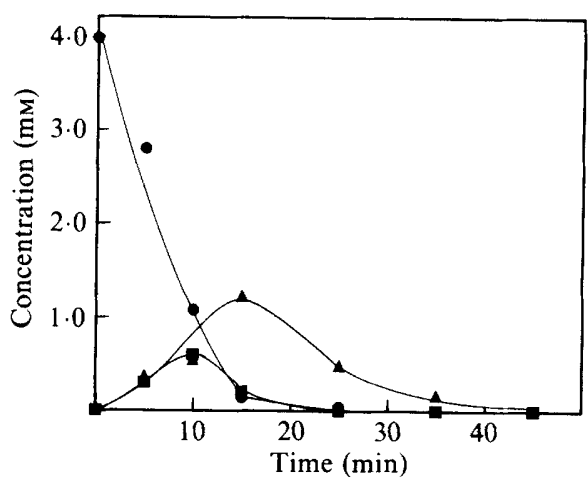

Fig. 2

Fig. 1. Growth of $C$. acidovorans NBA-10 at various concentrations of 4-NBA. The initial concentrations of 4-NBA (mM) were $0.5(\mathbf{O})$, $1.0(\mathbf{D}), 2.0(\nabla) 4.0(\bullet)$ and $5.0(\Delta)$

Fig. 2. Degradation of 4-NBA $(\bullet)$ and formation of 4-HABA $(\boldsymbol{A})$ and 3,4-diHBA $(\boldsymbol{\square})$ by resting cells of C. acidovorans NBA-10 grown on 4-NBA. The cell suspensions $(5.6 \mathrm{mg}$ protein in $10 \mathrm{ml})$ were incubated in the presence of phenanthroline $(0.1 \mathrm{~mm})$ under oxygenlimited conditions.

organism was obligately aerobic, did not grow above $41^{\circ} \mathrm{C}$ and lacked diffusible fluorescent pigment. The API test revealed reduction of nitrate, assimilation of mannitol, gluconate, adipate, malate and phenylacetate. Other biochemical tests revealed no acid production from glucose, alkalization on tartrate and acetamide, restricted hydrolysis of gelatine and sensitivity to polymyxin B. Furthermore, NBA-10 utilized $p$-hydroxybenzoate, $m$-hydroxybenzoate and Simmon's citrate. On the basis of these taxonomic and biochemical characteristics strain NBA-10 was identified as a Comamonas acidovorans strain according to Willems et al. (1991).

The following compounds served as sole carbon and energy source: 4-NBA, 3,4-diHBA, 4-HBA, acetate and succinate. No growth occurred with 4-ABA, or 3-nitroand 2-nitrobenzoate. The growth of NBA-10 on 4-NBA was dependent on the concentration of 4-NBA; a lag phase of $10 \mathrm{~h}$ was observed at an initial concentration of 4 mM-4-NBA and no growth at all was observed at concentrations above $5 \mathrm{~mm}$ (Fig. 1). The doubling time of strain NBA-10 on 2 mM-4-NBA was $2 \mathrm{~h}$ as calculated from the growth curve.

\section{Degradation of various nitro-aromatics under resting cell conditions}

Cells grown on 4-NBA oxidized 4-NBA, 4-NOBA, 4HABA and 3,4-diHBA but no enhanced oxygen uptake was recorded with either 4-HBA or 4-ABA. Cells grown on 3,4-diHBA or 4-HBA oxidized neither 4-NBA nor 4NOBA nor 4-HABA (Table 1).
Table 1. Rates of oxygen uptake by washed cell suspensions of C. acidovorans NBA-10 grown on various carbon sources

Rates of oxygen uptake are expressed as $\mathrm{nmol} \mathrm{O}_{2}$ consumed min $^{-1}$ (mg protein) $)^{-1}$ after correction for the endogenous oxygen uptake rate.

\begin{tabular}{lcccc}
\hline \hline & \multicolumn{4}{c}{ Oxygen uptake } \\
\cline { 2 - 5 } & \multicolumn{4}{c}{ Growth substrate: } \\
Substrate tested & 4-NBA & 4-HBA & 3,4-diHBA & Succinate \\
\hline 4-Nitrobenzoate & 160 & $<5$ & $<5$ & $<5$ \\
4-Nitrosobenzoate & 150 & $<5$ & $<5$ & $<5$ \\
4-Hydroxylaminobenzoate & 180 & $<5$ & $<5$ & $<5$ \\
4-Hydroxybenzoate & $<5$ & 230 & 10 & 5 \\
3,4-Dihydroxybenzoate & 380 & 180 & 280 & 20 \\
4-Aminobenzoate & $<5$ & $<5$ & $<5$ & $<5$ \\
4-Nitrophenol & $<5$ & 20 & 10 & 10 \\
Succinate & 20 & 15 & 20 & 400 \\
\hline \hline
\end{tabular}

4-NBA metabolism by washed cells was also examined by measuring the disappearance of the substrate by means of HPLC. Cells grown on 4-NBA in a chemostat readily degraded 4-NBA aerobically [220 $\mathrm{nmol} 4-\mathrm{NBA}$ $\left.\mathrm{min}^{-1}(\mathrm{mg} \text { protein })^{-1}\right]$ and a stoichiometric amount of ammonium was detected as degradation product. Under strict anaerobic conditions, no 4-NBA was degraded. Incubating whole cells with 4-NBA under oxygenlimited conditions did result in the accumulation of traces of other degradation products apart from ammonium. A more pronounced accumulation of these products (detected by HPLC) was observed when under oxygenlimited conditions phenanthroline $(0 \cdot 1 \mathrm{mM})$ was added as an inhibitor of, presumably, the 3,4-diHBA dioxygenase (Fig. 2). One of these compounds accumulated was 


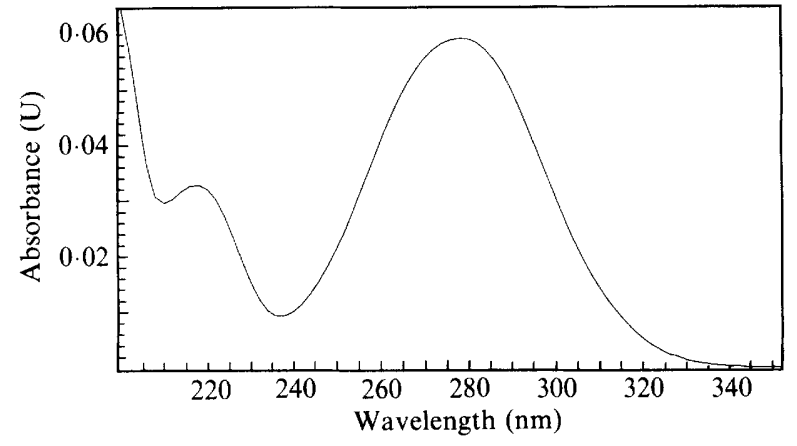

Fig. 3. Absorption spectrum of chemically synthesized 4hydroxylaminobenzoate.

identified as 3,4-diHBA on the basis of HPLC retention time and absorption spectrum.

Because the other compound did not match the characteristics of a range of possible intermediates tested, e.g. 4-HBA or 4-ABA, additional efforts for identification were necessary. 4-NOBA and 4-HABA were synthesized and their identity and purity were checked by H-NMR. NMR spectra recorded in DMSO$d_{6}$ revealed the proton shifts for 4-NOBA to be $\delta$ (p.p.m.) $8.01 \mathrm{~d}(2 \mathrm{H})$ and $8.24 \mathrm{~d}(2 \mathrm{H})$, and for 4-HABA $\delta$ (p.p.m.) $6.82 \mathrm{~d}(2 \mathrm{H})$ and $7.74 \mathrm{~d}(2 \mathrm{H})$. The retention time of the chemically synthesized 4-HABA, as well as its absorbance spectrum (Fig. 3) determined by stop-flow scanning HPLC, were identical to these characteristics of the unknown compound found in the incubation mixture. The identity of the so-far unknown intermediate was additionally confirmed by extracting the compound via preparative HPLC followed by GC/MS analysis. However, procedures using diazomethane to methylate 4-NOBA and 4-HABA prior to GC/MS analysis resulted in degradation products. Therefore, direct current mass spectrometric analysis was used. For both the synthesized 4-HABA and for the extracted compound a parent ion $m / e$ of 153 was found. In addition four fragment ions were detected at $m / e 136\left(\mathrm{C}_{7} \mathrm{H}_{6} \mathrm{NO}_{2}\right)$, $108\left(\mathrm{C}_{6} \mathrm{H}_{6} \mathrm{NO}\right), 120\left(\mathrm{C}_{7} \mathrm{H}_{6} \mathrm{NO}\right)$ and $90\left(\mathrm{C}_{6} \mathrm{H}_{6} \mathrm{~N}\right)$.

Incubation of 4-NBA-grown cells aerobically with 4NOBA resulted in a rapid degradation of 4-NOBA. In the presence of phenanthroline under oxygen-limited condition a transient accumulation of 4-HABA was found (Fig. 4).

\section{Degradation of 4-NBA in cell extracts}

From the experiments with whole cells, it was assumed that the first step in the degradation of 4-NBA is catalysed by a reductase via 4-NOBA to 4-HABA. Activity of the 4-NBA reductase was measured both by spectrophotometrically recording NADPH oxidation and by HPLC measuring the disappearance of 4-NBA in the presence of NADPH. Cell-extracts of strain NBA-10 did indeed contain a NAD(P)H-dependent 4-NBA reductase activity, which was present when cell were grown on 4-NBA but not when grown on other substrates. The specific acitivity of the 4-NBA reductase measured as NADPH oxidation was $1060 \mathrm{nmol} \mathrm{min}^{-1}$ (mg protein) $)^{-1}$ and $550 \mathrm{nmol}$ 4-NBA $\min ^{-1}(\mathrm{mg}$ protein $)^{-1}$ as measured directly by the HPLC method.

Under anaerobic conditions, an accumulation of 4HABA and 3,4-diHBA was observed (Fig. 5). Under both aerobic and oxygen-limited conditions the same 4-NBA reductase activity was measured, although only traces $(<0.01 \mathrm{~mm})$ of 4 -HABA and 3,4-diHBA accumulated.

\section{Partial purification and characterization of 4-NBA reductase}

Purification of the 4-NBA-reductase was assessed by monitoring NADPH oxidation in the presence of 4NBA. The enzyme purification scheme (Table 2) consisted of three steps and resulted in a 18.4-fold purification. After Mono Q chromatography, only $3.2 \%$ of the 4-NBA reductase activity from the cell-extract was recovered.

Gel filtration, hydroxyapatite chromatography, and Cibracon blue affinity chromatography were tested as subsequent purification steps. However, no increase in the specific activity of 4-NBA reductase was obtained by any of these methods. After gel electrophoresis of the purified 4-NBA reductase $(20 \mu \mathrm{g})$ only one major band was detected, and consequently no other efforts were undertaken to further purify the enzyme.

The partially purified enzyme was characterized. The optimal temperature of the enzyme reaction was at $30{ }^{\circ} \mathrm{C}$. Only $20 \%$ of the maximal activity was retained at $40^{\circ} \mathrm{C}$. Enzymic activity was completely absent at $45^{\circ} \mathrm{C}$. Heating the enzyme for $10 \mathrm{~min}$ at $40^{\circ} \mathrm{C}$ resulted in complete loss of activity.

Incubation of the partially purified enzyme with a range of possible substrates revealed a rather narrow substrate specificity. Only 4-nitrophenyl chloride, 4nitrophenyl acetate and 4-nitrophenylalanine were degraded, albeit at very low rates of $0.5,7.0$ and $0.5 \%$ respectively of the specific activity found with 4-NBA. No activity was found with 4-halobenzoates, 4-hydroxy-, 4-hydroxylamino- and 4-aminobenzoate or with benzoate.

The degradation rate of 4-NBA with NADPH was 15 times higher than with NADH. The difference in specific activities of the 4-NBA reductase with either NADPH or NADH did not change during the purification procedure. Adding FAD or FMN or metal ions to 


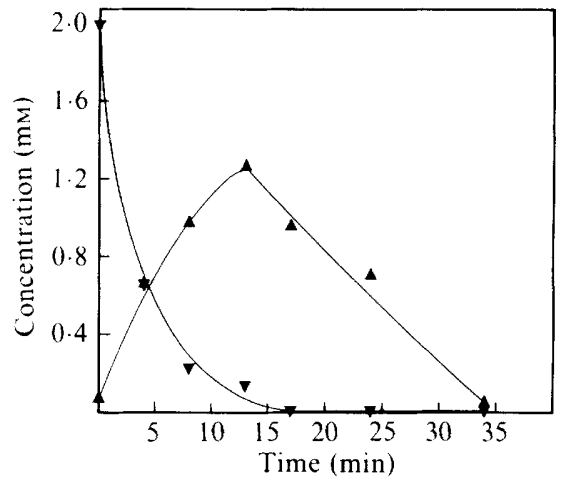

Fig. 4

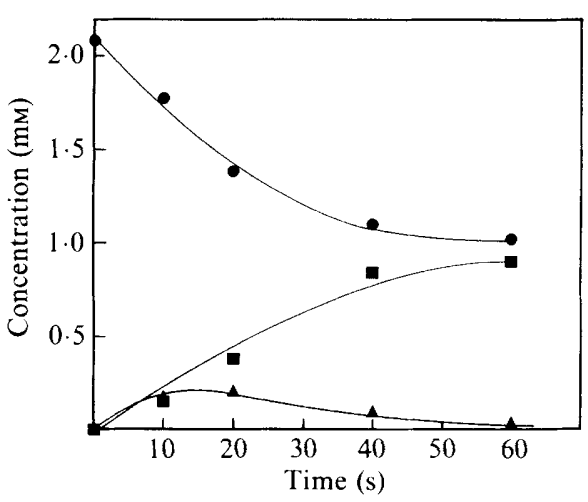

Fig. 5

Fig. 4. Degradation of 4-NOBA $(\boldsymbol{\nabla})$ to 4-HABA $(\boldsymbol{\Lambda})$ by resting cells of $C$. acidovorans NBA-10 grown on 4-NBA. The cell suspensions $(0.8 \mathrm{mg}$ protein in $10 \mathrm{ml})$ were incubated in the presence of phenanthroline $(0.1 \mathrm{mM})$ under oxygen-limited conditions.

Fig. 5. Anaerobic degradation of 4-NBA $(\boldsymbol{)})$ and formation of 4-HABA $(\boldsymbol{A})$ and 3,4-diHBA $(\boldsymbol{\square})$ in cell extracts. The incubations contained $2.1 \mathrm{mg}$ protein in $1 \mathrm{ml}$.

Table 2. Partial purification of 4-NBA reductase from $C$. acidovorans $N B A-10$

1 Unit (U) is $1 \mathrm{nmol}$ 4-NBA degraded.

\begin{tabular}{lcccccc}
\hline \hline $\begin{array}{l}\text { Purification } \\
\text { step }\end{array}$ & $\begin{array}{c}\text { Vol. } \\
(\mathrm{ml})\end{array}$ & $\begin{array}{c}\text { Total } \\
\text { act. } \\
(\mathrm{U})\end{array}$ & $\begin{array}{c}\text { Protein } \\
\left(\mathrm{mg} \mathrm{ml}^{-1}\right)\end{array}$ & $\begin{array}{c}\text { Sp. act. } \\
\left(\mathrm{U} \mathrm{min}^{-1} \mathrm{mg}^{-1}\right)\end{array}$ & $\begin{array}{c}\text { Yield } \\
(\%)\end{array}$ & $\begin{array}{c}\text { Purification } \\
(- \text { fold })\end{array}$ \\
\hline Cell-free extract & 41 & 580 & $22 \cdot 4$ & 630 & 100 & 1 \\
$\left(\mathrm{NH}_{4}\right)_{2} \mathrm{SO}_{4}(35-55 \%)$ & 10 & 312 & $49 \cdot 6$ & 630 & 54 & 1 \\
DEAE & 30 & 182 & $1 \cdot 1$ & 5600 & 31 & $8 \cdot 9$ \\
Mono Q (FPLC) & 5 & 18 & $0 \cdot 3$ & 11600 & $3 \cdot 2$ & $18 \cdot 4$ \\
\hline \hline
\end{tabular}

the incubation mixture did not enhance the specific activity.

Incubation of $4-\mathrm{NBA}$ reductase $[11600 \mathrm{nmol} 4-\mathrm{NBA}$ $\min ^{-1}$ (mg protein) ${ }^{-1}$ ] with NADPH and 4-NBA revealed a stoichiometric conversion of 4-NBA to 4-HABA. The amount of NADP formed was approximately twice the amount of 4-NBA degraded or 4-HABA formed (results not shown). No 4-NOBA was detected during this incubation. Under both anaerobic and aerobic conditions, the same rate of 4-NBA reduction was found. When 4-NOBA was offered as alternative substrate, no conversion was found unless NADPH was added. However, in the absence of the 4-NBA reductase but in the presence of NADPH, 4-NOBA was chemically unstable. Apart from 4-HABA, some unidentified degradation products were detected also.

\section{Discussion}

Bacteria growing on 4-NBA as sole carbon and energy source were easily isolated from soil. In the isolate Comamonas acidovorans NBA-10 the initial attack in the degradation of 4-NBA is on the nitro-group as reported for the 4-NBA-degrading bacterium Pseudomonas fluorescens (Durham, 1958; Cartwright \& Cain, 1959b) and for Nocardia erythropolis (Cartwright \& Cain, $1959 a, b)$. However, from the growth characteristics and simultaneous adaptation experiments it appeared that 4NOBA and 4-HABA but not 4-ABA or 4-HBA are intermediates in the degradation of 4-NBA by strain NBA-10. This was supported by demonstrating that when grown on 4-NBA under oxygen-limited conditions cells excreted 4-HABA and 3,4-diHBA. Furthermore, after partial purification of the 4-NBA reductase it was shown that with 2 mols NADPH present 1 mol of 4-NBA was converted stoichiometrically to 4-HABA. These results clearly demonstrate that the reduction of 4-NBA by strain NBA-10 does not involve the complete reduction of 4-NBA to 4-ABA. Such a pathway, without the involvement of an amino derivative, was suggested initially by $\mathrm{Ke}$ et al. (1959) on the basis of simultaneous adaptation experiments in the degradation of 2-nitrobenzoate by a Flavobacterium. The reduction of the nitrogroup of 4-NBA by strain NBA-10 to an hydroxylaminogroup is the first example of an incomplete reduction 


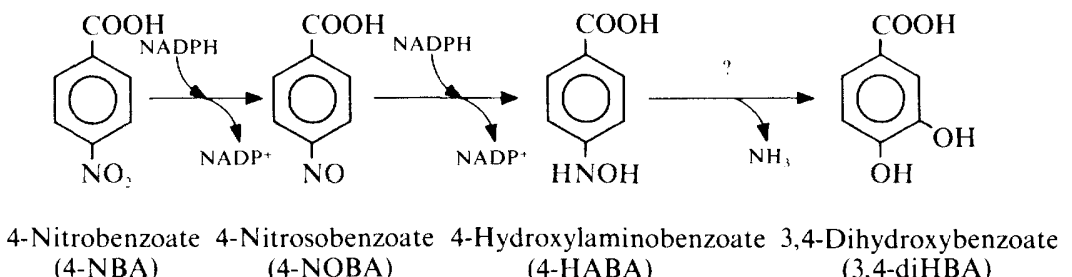

$\begin{array}{llll}(4-\mathrm{NBA}) & \text { (4-NOBA) } & (3,4-\mathrm{diHBA})\end{array}$

Fig. 6. Proposed degradative pathway of 4-NBA by C. acidovorans NBA-10.

involved in the degradative pathways of nitro-aromatic compounds.

From the arguments given below we concluded that no similar 4-NBA reductases from bacterial sources other than $C$. acidovorans strain NBA-10 have been purified. Three methyl-4-nitrobenzoate reductases with a broad substrate specificity purified from Escherichia coli exhibited 4-NBA reductase activity also, although their activities were rather low. The characteristics of these reductases (Kitamura et al., 1983) do not match the properties of 4-NBA reductase from strain NBA-10, since after incubation with methyl-4-nitrobenzoate methyl-4-aminobenzoate was detected as well as methyl4-hydroxylaminobenzoate; also the dialysed NAD $(\mathrm{P}) \mathrm{H}-$ dependent $E$. coli reductases required addition of FMN for activity. From results obtained after purification of $p$-dinitrobenzene reductase from Nocardia V, it was also similarly assumed that the three subsequent steps involved in $p$-dinitrobenzene reduction to $p$-nitroaniline were catalysed by only one reductase (Villanueva, 1964). Furthermore, in Bacteroides fragilis four nitropyrene reductases were detected with different properties, one of them requiring NADH while the other reductases were NADPH linked. The purified nitropyrene reductase also seemed to catalyse all three steps of nitropyrene reduction (Kinouchi \& Onishi, 1983).

Fractionation by anion-exchange chromatography of the 4-NBA reductase from $C$. acidovorans NBA-10 resulted in an 18.4-fold purification but considerable loss of activity occurred (Table 2). Other purification procedures tested gave even less satisfactory results. This loss of activity could not be prevented by adding antioxidants (dithiothreitol) or by excluding oxygen during purification.

The further degradation of 4-HABA in C. acidovorans NBA-10 is puzzling. Based on results from adaptation experiments (Table 1), from oxygen-limited incubations of whole cells (Fig. 2) as well as from results with crude cell-free extracts (Fig. 5), it would seem that 4-HABA is degraded to 3,4-diHBA (Fig. 6). However, attempts to characterize the enzyme involved in the conversion of 4HABA into 3,4-diHBA have not been successful because activity was lost upon dialysing extracts.
The authors are grateful to A. van Veldhuizen for performing the NMR analysis and to J. A. van Rhijn (RIKILT, Wageningen) for performing the MS analysis.

\section{References}

Bauer, H. \& Rosenthal, S. M. (1944). 4-Hydroxylaminobenzene sulfonamide, its acetyl derivatives and diazotization reaction. Journal of the American Chemical Society 185, 611-614.

BruHN, C., LenKe, H. \& KNACKMUSS, H. J. (1987). Nitrosubstituted aromatic compounds as nitrogen source for bacteria. Applied and Environmental Microbiology 53, 208-210.

CAIN, R. B. $(1966 a)$. Induction of an anthranilate oxidation system during the metabolism of ortho-nitrobenzoate by certain bacteria. Journal of General Microbiology 42, 197-217.

CAIN, R. B. (1966b). Utilization of anthranilic and nitrobenzoic acids by Nocardia opaca and a Flavobacterium. Journal of General Microbiology 42, 219-235.

CAIN, R. B. \& CARTWRIGHT, N. J. (1960). Intermediary metabolism of 4-nitrobenzoic acids by bacteria. Nature, London 185, 868-869.

CARTWRIGHT, N. J. \& CAIN, R. B. (1959a). Bacterial degradation of the nitrobenzoic acids. Biochemical Journal 71, 248-261.

Cartwright, N. J. \& CAIN, R. B. (1959b). Bacterial degradation of the nitrobenzoic acids. 2. Reduction of the nitro group. Biochemical Journal 73, 305-314.

DURHAM, N. N. (1956). Bacterial oxidation of $p$-aminobenzoic acid by Pseudomonas fluorescens. Journal of Bacteriology 72, 333-336.

Durham, N. N. (1958). Studies on the metabolism of $p$-nitrobenzoic acid. Canadian Journal of Microbiology 4, 14I-148.

Germanier, R. \& WuhrmanN, K. (1963). Ueber den aeroben mikrobiellen Abbau aromatischer Nitroverbindungen. Pathologia Microbiologia 26, 569-578.

Groenewegen, P. E. J., VAN den Tweel, W. J. J. \& De Bont, J. A. M (1992). Anaerobic bioformation of 4-hydroxybenzoate from 4chlorobenzoate by the coryneform bacterium NTB-1. Applied Microbiology and Biotechnology 36, 541-547.

HALLER, H. D. \& FinN, R. K. (1978). Kinetics of biodegradation of $p$-nitrobenzoate and inhibition by benzoate in a pseudomonad. Applied and Environmental Microbiology 35, 890-896.

Ke, Y.-H., GeE, L. L. \& DuRham, N. N. (1958). Mechanism involved in the metabolism of nitrophenylcarboxylic acid compounds by microorganisms. Journal of Bacteriology 77, 593-598.

KINOUCHI, T. \& OHNISHI, Y. (1983). Purification and characterization of 1-nitropyrene nitroreductases from Bacteroides fragilis. Applied and Environmental Microbiology 46, 596-604.

Kitamura, S., Narai, N. \& Tatsumi, K. (1983). Studies on bacterial nitroreductases. Enzymes involved in reduction of aromatic nitro compounds in Escherichia coli. Journal of Pharmacobio-Dynamics 6 , 18-24.

LiU, D., Thomson, K. \& Anderson, A. C. (1984). Identification of nitroso compounds from biotransformation of 2,4-dinitrotoluene. Applied and Environmental Microbiology 47, 1295-1298.

McCormick, N. G., Feeherry, F. E. \& Levinson, H. S. (1976). Microbial transformation of 2,4,6-trinitrotoluene and other nitroaromatic compounds. Applied and Environmental Microbiology 31, 949958. 
Rafil, F., Franklin, W., Heflich, R. H. \& Cerniglia, C. E. (1991). Reduction of nitroaromatic compounds by anaerobic bacteria isolated from the human gastrointestinal tract. Applied and Environmental Microbiology 57, 962-968.

SCHACKMANN, A. \& MülleR, R. (1991). Reduction of nitroaromatic compounds by different Pseudomonas species under aerobic conditions. Applied Microbiology and Biotechnology 34, 809-813.

SPAIN, J. C., Wyss, O.\& GiBSON, D. T. (1979). Enzymatic oxidation of p-nitrophenol. Biochemical and Biophysical Research Communications 88, 634-641

Thissen, H. H. W. \& Henderson, P. Th. (1973). Interference of the reduction of $p$-nitrobenzoate in $E$. coli by nitrofurantoin. Xenobiotica 3, 399-407.

Villanueva, J. R. (1964). The purification of a nitroreductase from Nocardia V. Journal of Biological Chemistry 3, 773-776.
Willems, A., De Ley, J., Gillis, M. \& Kersters, K. (1991) Comamonadaceae, a new family encompassing the acidovorans rRNA complex, including Variovorax paradoxus gen. nov., comb., nov., for Alcaligenes paradoxus (Davis, 1969). International Journal of Systematic Bacteriology 41, 445-450.

Yamashina, I., Shikata, S. \& Egami, F. (1954). Enzymatic reduction of aromatic nitro, nitroso and hydroxylamino compounds. Bulletin of the Chemical Society of Japan 27, 42-45.

ZEYER, J. (1980). Abbau aromatischen Nitroverbindungen. Das Gasund Wasserfach Wasser Abwasser 129, 25-27.

ZEYER, J. \& KeARNEY, P. C. (1984). Degradation of $o$-nitrophenol and $m$-nitrophenol by a Pseudomonas putida. Journal of Agricultural and Food Chemistry 32, 238-242. 